PREPARED FOR THE U.S. DEPARTMENT OF ENERGY, UNDER CONTRACT DE-AC02-76-CHO-3073

PPPL-2919

UC $-420,427$

A MEAN FIELD OHM'S LAW FOR COLLISIONLESS PLASMAS

BY

H. BIGLARI AND P.H. DIAMOND

JUNE, 1993
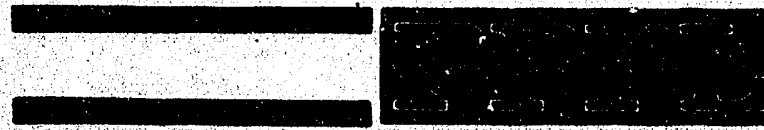

Paincerton

OLASMA EHY

LAOEATEAY

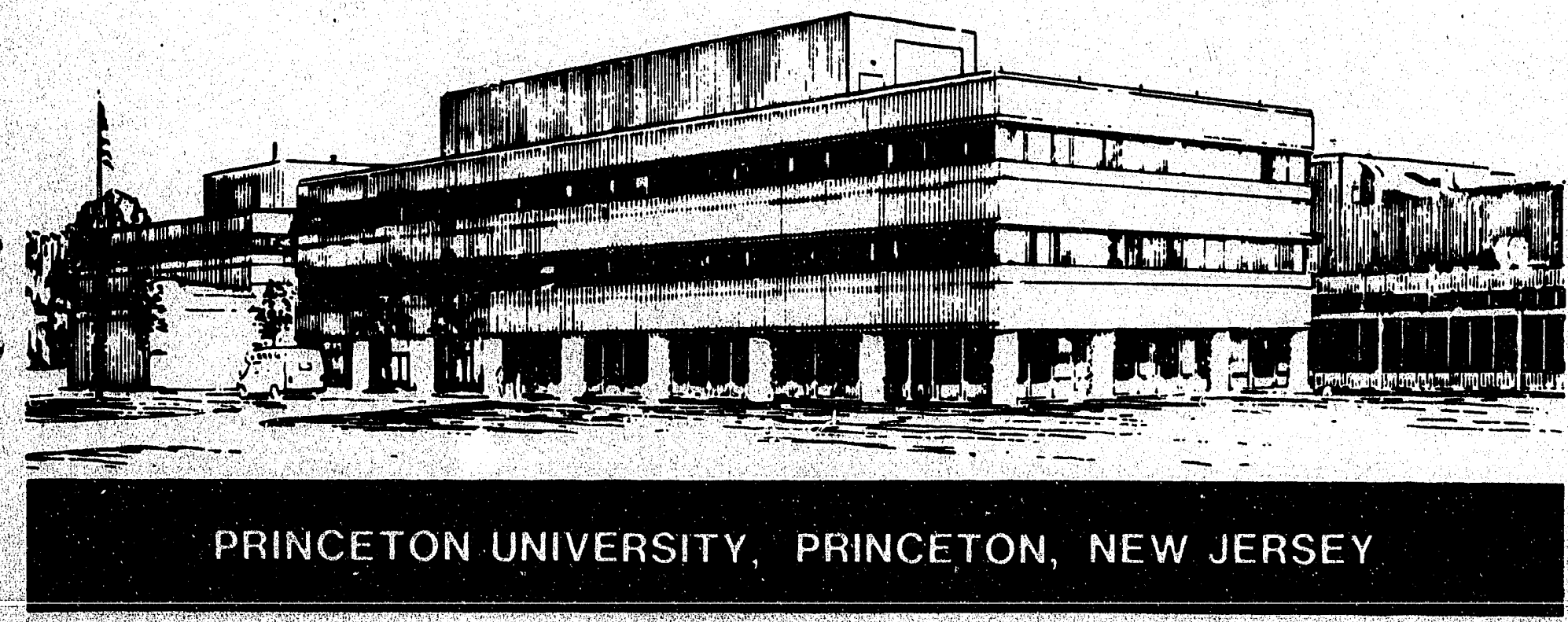




\section{NOTICE}

This report was prepared as an account of work sponsored by an agency of the United States Government. Neither the United States Government nor any agency thereof, nor any of their employees, makes any warranty, express or implied, or assumes any legal liability or responsibility for the accuracy, completeness, or usefulness of any information, apparatus, product, or process disclosed, or represents that its use would not infringe privately owned rights. Reference herein to any specific commercial produce, process, or service by trade name, trademark, manufacturer, or otherwise, does not necessarily constitute or imply its endorsement, recommendation, or favoring by the United States Government or any agency thereof. The views and opinions of authors expressed herein do not necessarily state or reflect those of the United States Government or any agency thereof.

\section{NOTICE}

This report has been reproduced from the best available copy.

Available in paper copy and microfiche.

Number of pages in this report: 10

DOE and DOE contractors can obtain copies of this report from:

Office of Scientific and Technical Information

P.O. Box 62

Oak Ridge, TN 37831;

(615) $576-8401$.

This report is publicly available from the:

National Technical Information Service

Department of Commerce

5285 Port Royal Road

Springfield, Virginia 22161

(703) $487-4650$ 
. Warch 1993

\title{
A MEAN FIELD OHM'S LAW FOR COLLISIONLESS PLASMAS
}

\author{
H. Biglari \\ Princeton Plasma Physics Laboratory, Princeton University, \\ P.O. Box 451, Princeton, NJ 08543 \\ and \\ P. H. Diamond \\ Department of Physics 0139, University of California at San Diego. \\ La Jolla, California 92093
}

A mean field Ohm's law valid for collisionless plasmas is derived kinetically. It is shown that contrary to conventional thinking, the resulting hyper-resistivity is significantly smaller than its fluid counterpart due to the fact that the turbulent decorrelation rate is linked to the rapid electron ballistic motion rather than the slower nonlinear mixing time. Moreover, the off-diagonal contributions to the parallel electron momentum flux are shown to result in $\mathrm{Ohm}$ 's law renormalizations that dwarf the current diffusivity and break radial parity symmetry. Thus, the conventional wisdom of tearing and twisting parity solutions appears to be vitiated in the turbulent, collisionless regime.

PACS \# 52.35.Ra 52.25.Gj 52.25.Dg 52.55.Dy

Submitted for Publication to Physics Fluids Letters B

${ }^{\dagger}$ Also: General Atomics, San Diego, CA 92138

Misith

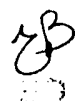


Resistive fluid models have served plasma physics as a useful paradigm for turbulence and anomalous transport. However, the utility of such models for describing presentgeneration experiments which operate at very low electron collisionalities is, at best, moot. Hence, there is clear motivation to extend the intuitively satisfying picture of resistive magnetohydrodynamics (MHD) into the collisionless domain. Generally speaking, the goal of such investigations is twofold: first, to understand the mechanism of electron momentum transport and its impact on current profile evolution, and second, to uncover possible fluctuation-driven dissipation mechanisms (i.e., turbulent electron viscosity or hyper-resistivity) which effectively replace resistivity as the agent of field-fluid decoupling in a collisionless plasma.

The concept of a turbulent electron viscosity or hyper-resistivity is, by now, wellestablished in the plasma literature. Such an effect was originally proposed by Schmidt and Yoshikawa ${ }^{1}$ as a possible explanation for anomalous skin penetration in tokamaks. Later, an ad hoc anomalous electron viscosity term was also invoked by Kaw, Valeo, and Rutherford $\mathrm{d}^{2}$ as a means for accelerating tearing mode growth, and linking such accelerated growth to magnetic field-line stochasticity which, in turn, follows magnetic island overlap during a major disruption. The problem was reformulated kinetically by Jacobsen and Moses, ${ }^{3}$ who linked the anomalous electron viscosity to the velocity-integrated Rechester-Rosenbluth ${ }^{4}$ collisionless magnetic diffusion coefficient. Strauss ${ }^{5}$ and others ${ }^{b}$ recognized that a hyper-resistivity and associated counter-terms (negative resistivity) enter the picture as a consequence of the spectral transfer of mean square flux in reduced MHD turbulence. Subsequently, Bhattacharjee and Hameiri ${ }^{7}$ and Boozer ${ }^{8}$ derived the form of the hyper-resistivity from general considerations of selective dissipation (helicity vs. energy) with application to dynamo theory and Taylor relaxation. Craddock ${ }^{3}$ discussed the renormalization of the generalized Ohm's law, incorporating parallel density gradients. More recently, Itoh et al. ${ }^{10}$ have invoked the concept of a hyper-resistivitydriven MHD interchange-ballooning mode as the basis of a theory of $L$-mode confinement in tokamaks and stellarators (cf. also Connor ${ }^{11}$ ). In that theory, the anomalous electron viscosity was linked to the random $\mathbf{E} \times \mathbf{B}$ convection of current fluctuations, i.e., it arises as a nonlinear electron inertia effect. However, as already mentinned, the relevance of a fluid prescription for collisionless tokamak discharges is highly questionable. Finally. Drake and Kleva ${ }^{12}$ have applied the concept of anomalous electron diffusion to the problem of collisionless reconnection amd the sawtooth crash. Thus, it can be seen that the question of hyper-resistivity is one of broad scope and importance, applicable to 1 roblems as diverse as anomalous tearing mode growth, reversed field pinch (RFP) relaxation. $L$-mode anomalous transport in tokamaks, and magnetic reconnection.

In this Letter, we present a systematic procedure for deriving a mean field (MF) Ohm's law for a collisionless plasma. The procedure is equally applicable to examining both mean profile evolution and test wave response. The approach, which is analogous to the procedure used for deriving the familiar "dynamo" equation in MF electrodynamics,${ }^{13}$ is to calculate the modulations in the radial flux of parallel electron momentum which are induced by a test wave introduced into a background turbulent bath of am- 
bient fluctuations. For brevity and simplicity, this analysis is limited to the case of an electrostatic turbulent background. As we shall discuss, the conclusions are generic and easily extended to the case of an electromagnetic bath. It will be seen that the simple fluid picture ${ }^{10}$ not only significantly overestimates the level of current transport, but also fails to capture off-diagonal "current pinch" terms which actually dominate the diagonal (hyper-resistive) current diffusion.

We begin our derivation with the nonlinear drift kinetic equation (NLDKE) for the fluctuating electron distribution function:

$$
\left(\frac{\partial}{\partial t}+v_{\|} \hat{\mathbf{e}}_{\|} \cdot \boldsymbol{\nabla}\right) \delta f_{e}+\delta \mathbf{v}_{E} \cdot \boldsymbol{\nabla}\left(\delta f_{e}+F_{M_{e}}\right)=\frac{e}{m_{e}} \delta E_{\|} \frac{\partial F_{M e}}{\partial v_{\|}}
$$

where $f_{e}=F_{M e}+\delta f_{e}, F_{M e}=\left(n_{e} / \pi^{1 / 2} v_{t e}\right) \exp \left\{-\left[v_{\|}-v_{0}(r)\right]^{2} / v_{t e}^{2}\right\}$ is a shifted electron Maxwellian, and $\delta \mathbf{v}_{E}=(c / B) \hat{\mathbf{e}}_{\|} \times \boldsymbol{\nabla} \delta \phi$ is the $\mathbf{E} \times \mathbf{B}$ velocity. In writing Eq. (1), we have ignored electron-ion collisions which give rise to the usual resistivity in Ohm's law. Thus, the Ohm's law which we derive is valid for $\nu_{e i} / \omega_{t e} \ll 1$, where $\nu_{e i}$ is the electron-ion collision frequency, and $\omega_{t e}=k_{\|} v_{t e}$ is the electron transit frequency. Note for example that for the Tokamak Fusion Test Reactor (TFTR), $\nu_{e i} / \omega_{t e}$ ranges from $2 \times 10^{-4}$ in the plasma center to 0.3 at the plasma edge, so that the entire plasma is in the collisionless regime by this definition. Integrating over $v_{\|}$, we obtain:

$$
\delta E_{\|}+\frac{1}{n_{e} e} \nabla_{\|} \delta p_{e}-\frac{4 \pi}{\omega_{p e}^{2}} \frac{\partial \delta j_{\|}}{\partial t}-\nabla \cdot \delta \Gamma_{e}=0
$$

where $\delta \Gamma_{e}=\left(4 \pi / \omega_{p e}^{2}\right) \delta\left\langle\hat{j}_{\|} \hat{\mathbf{v}}_{E}\right\rangle$ is the modulation in the electron momentum flux induced by the test wave, the angular brackets denote a spectral average over the bath of shortwavelength background turbulence, and the fields associated with the background turbulence have been 'hatted' to distinguish them from the fields associated with the test wave (denoted with a ' $\delta$ '). The first term on the lhs is the electrostatic field, $\delta E_{\|}=-\nabla_{\|} \delta 0$. the second represents parallel compression, the third represents the influence of electron inertia, while the last term represents the induced modulation in radial iransport. We now evaluate this last term using the nonadiabatic electron distribution function:

$$
\begin{aligned}
\Gamma_{e}= & -i \frac{4 \pi e}{\omega_{p e}^{2}} \frac{c}{B} \int d v_{\|} v_{\|}\left\langle k_{y} \hat{\phi} \hat{f}_{e}\right\rangle \\
= & \frac{T_{e}}{e} \sum_{k} k_{y} \rho_{e} \frac{\omega_{k}}{\omega_{t e}^{2}} \exp \left(-\frac{\omega_{k}^{2}}{\omega_{t e}^{2}}\right) W_{k} \\
& \times\left(\omega_{k}-k_{\|} v_{0}-\left\{2\left(\frac{\omega_{k}}{\omega_{t e}}-\frac{v_{0}}{v_{t e}}\right) \omega_{* j}+\omega_{* n}+\left[\left(\frac{\omega_{k}}{\omega_{t e}}-\frac{v_{0}}{v_{t e}}\right)^{2}-\frac{1}{2} \omega_{* T}\right\}\right),\right.
\end{aligned}
$$

where $W_{k}=\left\langle\left|e \hat{\phi}_{k} / T_{e}\right|^{2}\right\rangle$ is the background fluctuation intensity, $\omega_{* n}=k_{y} \rho_{e} v_{t e} / L_{n}$. $\omega_{*} T=k_{y} \rho_{e} v_{t e} / L_{T e}, \omega_{* j}=k_{y} \rho_{e} d v_{0} / d r, L_{n}^{-1}=d \ln n_{e} / d r$, and $L_{T e}^{-1}=d \ln T_{e} / d r$. The first two terms on the last line represent the Doppler-shifted frequency, while the remaining terms are the current, density, and temperature gradient-driven fluxes, respectively. For simplicity, we will assume a drift wave-like background bath. Thus, $\omega_{k} \sim \omega_{* n}$. 
and since the electron velocity shift is sonic at best, $v_{0} / v_{t e} \sim\left(m_{e} / m_{i}\right)^{1 / 2} \ll 1$, and also $\omega_{k} / \omega_{t e} \sim\left(R / L_{n}\right) k_{y} \rho_{c} \ll 1$. Én passant, we note that our conclusions would be unaffected if we had assumed a drift Alfvén-like bath, since then, $\omega_{k} / \omega_{t e}=v_{A} / v_{t e}=$ $\left[\left(m_{e} / m_{i}\right)\left(T_{i} / T_{e}\right)\right]^{1 / 2} \beta^{-1 / 2} \ll 1$. Using parameters in the core of TFTR, for example. $\omega_{k} / \omega_{t e}$ is of order 0.05 for electrostatic microturbulence and 0.1 for Alfvénic turbulence. The electron current flux then reduces to

$$
\Gamma_{e} \simeq \frac{T_{e}}{e} \sum_{k} k_{y} \rho_{e} \frac{\omega_{k}}{\omega_{t e}^{2}}\left[\omega_{k}-k_{\|} v_{0}+2\left(\frac{\omega_{k}}{\omega_{t e}}-\frac{v_{0}}{v_{t e}}\right) \omega_{* j}+\omega_{* n}-\frac{\omega_{* T}}{2}\right] W_{k}
$$

If we now consider the modulation of this flux by the test wave-induced inhomogeneity. we find

$$
\begin{aligned}
\delta \Gamma_{e} \simeq \frac{T_{e}}{e} \sum_{k} k_{y} \rho_{e} \frac{\omega_{k}}{\omega_{t e}^{2}}( & {\left[\omega_{k}-k_{\|} v_{0}+2\left(\frac{\omega_{k}}{\omega_{t e}}-\frac{v_{0}}{v_{t e}}\right) \omega_{* j}+\omega_{* n}-\frac{\omega_{* T}}{2}\right] \delta W_{k} } \\
& \left.+k_{y} \rho_{e} v_{t e}\left[2\left(\frac{\omega_{k}}{\omega_{t e}}-\frac{v_{0}}{v_{t e}}\right) \nabla_{x} \frac{\delta j_{\|}}{j_{0}}+\nabla_{x} \frac{\delta n_{e}}{n_{e}}-\frac{1}{2} \nabla_{x} \frac{\delta T_{e}}{T_{e}}\right] W_{k}\right) .
\end{aligned}
$$

where $j_{0}=e n_{e} v_{t e}$. In other words, the test fluctuation induces modulations in the current. density, temperature, and the (background) turbulent spectrum. In order to evaluate the latter, we consider the random refraction of $\left(\mathbf{k}, \omega_{k}\right)$ drift wave packets ${ }^{14}$ propagating in a medium modulated by a long-wavelength, low-frequency $\left[\left(\mathbf{q}, \Omega_{q}\right) \ll\left(\mathbf{k}, \omega_{k}\right)\right]$ test wave. The wave packet (bath constituent) propagation is most conveniently described by the radial spectral width-averaged wave kinetic equation:

$$
\frac{\partial \delta N_{k}}{\partial t}+v_{g k, y} \frac{\partial \delta N_{k}}{\partial y}-\frac{\partial \delta \omega_{k}}{\partial y} \frac{\partial N_{k 0}}{\partial k_{y}}=0
$$

where $N_{k 0}(\mathbf{x}, \mathbf{k}, t)=k_{\perp}^{2} \rho_{s}^{2}\left[\partial\left(\omega_{k} \epsilon_{k}\right) / \partial \omega_{k}\right] W_{k}=k_{\perp}^{2} \rho_{s}^{2}\left(1+k_{\perp}^{2} \rho_{s}^{2}\right) W_{k} / 2$ is the pseudo-action density, $\mathbf{v}_{g k}=-\left(\omega_{k} \rho_{s} \mathbf{k}_{\perp}+\mathbf{v}_{*} / 2\right)\left\{2 \rho_{s} /\left(1+k_{\perp}^{2} \rho_{s}^{2}\right)\right]$ is the drift wave group velocity $\left(\mathbf{v}_{*}=\right.$ $\left.c_{s} \hat{\mathbf{e}}_{\|} \times \nabla \ln n_{e}\right), \omega_{k}=\omega_{k 0}+\delta \omega_{k}, \omega_{k 0}=\omega_{* n} /\left(1+k_{\perp}^{2} \rho_{s}^{2}\right)$, and

$$
\delta \omega_{k}(\mathbf{q})=\frac{k_{\perp}^{2} \rho_{s}^{2}}{1+k_{\perp}^{2} \rho_{s}^{2}} \mathbf{k}_{\perp} \cdot \delta \mathbf{v}_{E}=-i k_{y} \rho_{e} v_{t e} \frac{k_{\perp}^{2} \rho_{s}^{2}}{1+k_{\perp}^{2} \rho_{s}^{2}} \nabla_{x} \frac{e \delta \phi}{T_{e}}
$$

is the modulation induced in the background fluctuation oscillation frequency by the test wave. Fourier-analyzing the wave kinetic equation, we obtain the modulation of the action spectrum as background waves propagate at their group velocity through the inhomogeneous medium:

$$
\delta W_{k}(\mathbf{q})=2 \pi k_{y} \rho_{e} v_{t e} \frac{k_{\perp}^{2} \rho_{s}^{2}}{\left(1+k_{\perp}^{2} \rho_{s}^{2}\right)^{2}} \delta\left(\Omega_{q}-q_{y} v_{g k, y}\right) q_{y} \frac{\partial N_{k 0}}{\partial k_{y}} \nabla_{x} \frac{e \delta \phi}{T_{e}}
$$

Substituting Eq. (8) into Eq. (5), and plugging back into Eq. (2), we finally obtain the Fourier-analyzed Ohm's law:

$i\left(-q_{\|} v_{t e}+\nabla_{x} \cdot D_{W} \nabla_{x}\right) \frac{e \delta \phi_{q}}{T_{e}}-i q_{\|} v_{t e} \frac{\delta p_{\| q}}{p_{e}}+\left(-i \Omega_{q}+\nabla_{x} \cdot D_{J} \nabla_{x}\right) \frac{\delta j_{\| q}}{j_{0}}+\nabla_{x} \cdot D_{n} \nabla_{x}\left(\frac{\delta n_{q}}{n_{e}}-\frac{\delta T_{q}}{2 T_{e}}\right)=0$. 
where $\delta T_{q}$ is the fluctuating parallel temperature, and

$$
\begin{aligned}
D_{J} & =2 v_{t e}^{2} \sum_{k} k_{y}^{2} \rho_{e}^{2} \frac{\omega_{k}^{2}}{\omega_{t e}^{3}}\left(1-\frac{k_{\|} v_{0}}{\omega_{k}}\right) W_{k} \\
D_{n}= & v_{t e}^{2} \sum_{k} k_{y}^{2} \rho_{e}^{2} \frac{\omega_{k}}{\omega_{t e}^{2}} W_{k} \\
D_{W}\left(q_{y}, \Omega_{q}\right)= & 2 \pi v_{t e}^{2} \sum_{k} k_{y}^{3} \rho_{e}^{3} \frac{\omega_{k}}{\omega_{t e}^{2}} \frac{k_{\perp}^{2} \rho_{s}^{2}}{\left(1+k_{\perp}^{2} \rho_{s}^{2}\right)^{2}} \delta\left(\Omega_{q}-q_{y} v_{g k, y}\right) \\
& \times\left[\omega_{k}-k_{\|} v_{0}+2\left(\frac{\omega_{k}}{\omega_{t e}}-\frac{v_{0}}{v_{t e}}\right) \omega_{* j}+\omega_{* n}-\frac{\omega_{*} T}{2}\right] q_{y} \frac{\partial N_{k 0}}{\partial k_{y}}
\end{aligned}
$$

are the hyper-resistivity (current diffusivity), particle diffusivity, and spectral diffusivity. respectively.

Equation (9) is the main result of this Letter and can be seen to have several important and surprising implications for predictions of transport of parallel electron momentum and anomalous electron dissipation. First, the collisionless hyper-resistivity is a factor $\left(\omega_{k} / \omega_{t e}\right)^{3} \ll 1$ smaller than its naive fluid counterpart. ${ }^{10}$ The origin of this reduction factor becomes clear when we rewrite the hyper-resistivity in the form $D_{J}=$ $\sum_{k}\left\langle\left|\delta \mathbf{v}_{k}\right|^{2}\right\rangle \tau_{c k} F\left(\omega_{k} / \omega_{t e}\right)$, where $\delta \mathbf{v}_{k}$ is the turbulent velocity field, $\tau_{c k}$ is the decorrelation time, and $F\left(\omega_{k} / \omega_{t e}\right)$ is a factor related to parallel electron compression. The crucial point is the form of $\tau_{c k}$ and $F\left(\omega_{k} / \omega_{t e}\right)$. For collisionless electron transport, $\tau_{c k}^{-1}=\omega_{t e}$ as opposed to $\Delta \omega_{k} \sim \omega_{k} \ll \omega_{t e}$ in the simple fluid picture, ${ }^{10}$ i.e., the decorrelation rate is linked to the (rapid) electron transit frequency rather than the the (slower) nonlinear mixing time. Furthermore, $F\left(\omega_{k} / \omega_{t e}\right)=\left(\omega_{k} / \omega_{t e}\right)^{2} \ll 1$ in the collisionless regime, reflecting the tendency of parallel electron compressibility to render the electron response quasi-adiabatic. thus drastically reducing current diffusion.

It should be noted that simple fluid theory is intrinsically incapable of recovering this

- fundamentally kinetic result. Indeed, it might be expected that proper incorporation of parallel dynamics would recover the reductive factors of $\omega_{k} / \omega_{t e}$ in the kinetic result, since the origin of the latter is in parallel dynamics. In fact, as we will presently show, parallel compression only partially recovers the missing factors. Consider the renormalization of the simple, two-field system of equations:

$$
\begin{gathered}
\frac{\partial \delta j_{\|}}{\partial t}-e v_{t e}^{2} \nabla_{\|} \delta n_{e}+\nabla \cdot\left(\frac{c}{B} \delta j_{\|} \hat{\mathbf{e}}_{\|} \times \nabla \delta \phi\right)=0, \\
\frac{\partial \delta n_{e}}{\partial t}+\frac{1}{e} \nabla_{\|} \delta j_{\|}=0 .
\end{gathered}
$$

Equation (11) is the current evolution equation, where the second term represents parallel compression, while the last term is the turbulent $\mathbf{E} \times \mathbf{B}$ advection of the current, and Eq. (12) is the continuity equation. Our aim in adopting this reduced description is to keep only those terms that enter explicitly into the derivation of the fluid hyper-resistivity. Other terms have been dropped in the interest of keeping the argument as transparent 
as possible. To renormalize the nonlinear term, namely $(i c / B) \sum_{k} \hat{\mathbf{e}}_{\|} \cdot \mathbf{k} \times \mathbf{q} \delta \phi_{k} \delta j_{\| q^{\prime \prime}}^{(2)}$, we solve for the beat fields from

$$
\begin{gathered}
\left(\omega^{\prime \prime}+i \Delta \omega^{\prime \prime}\right) \delta j_{\| q^{\prime \prime}}^{(2)}+e v_{t e}^{2} q_{\|}^{\prime \prime} \delta n_{e q^{\prime \prime}}^{(2)}=i \frac{c}{B} \hat{\mathbf{e}}_{\|} \cdot \mathbf{k} \times \mathbf{q} \delta \phi_{k} \delta j_{\| q} \\
-\left(\omega^{\prime \prime}+i \Delta \omega^{\prime \prime}\right) \delta n_{e q^{\prime \prime}}^{(2)}+\frac{1}{e} q_{\|}^{\prime \prime} \delta j_{\| q^{\prime \prime}}^{(2)}=0
\end{gathered}
$$

to obtain

$$
\begin{aligned}
\delta j_{\| q^{\prime \prime}}^{(2)} & =i \frac{c}{B}\left(\omega^{\prime \prime}+i \Delta \omega^{\prime \prime}+\frac{\omega_{t e}^{\prime \prime 2}}{\omega^{\prime \prime}+i \Delta \omega^{\prime \prime}}\right)^{-1} \hat{\mathbf{e}}_{\|} \cdot \mathbf{k} \times \mathbf{q} \delta \phi_{k} \delta j_{\| q}, \\
& \simeq i \frac{c}{B} \frac{\omega^{\prime \prime}}{\omega_{t e}^{\prime 2}} \hat{\mathbf{e}}_{\|} \cdot \mathbf{k} \times \mathbf{q} \delta \phi_{k} \delta j_{\| q},
\end{aligned}
$$

where we have assumed $\omega_{t e}^{\prime \prime 2} \gg \omega^{\prime \prime} \sim \Delta \omega^{\prime \prime}$. The renormalized current equation in Fourier space is thus:

$$
-i q_{\|} v_{t e} \frac{\delta n_{q}}{n_{e}}+\left(-i \Omega_{q}+\nabla_{x} \cdot D_{J}^{f l u i d} \nabla_{x}\right) \frac{\delta j_{\| q}}{j_{0}}=0
$$

where

$$
D_{J}^{f l u i d}=v_{t e}^{2} \sum_{k} k_{y}^{2} \rho_{e}^{2} \frac{\omega_{k}}{\omega_{t e}^{2}} W_{k} .
$$

Thus, even accounting for parallel compression in the simple fluid picture, $D_{J}^{\text {fluid }} / D_{J} \simeq$ $\omega_{t e} / \omega_{k} \gg 1$. Note that in the analysis presented in Ref. 10, which ignores parallel compression even in the fluid picture, the hyper-resistivity is off by an extra two powers of $\omega_{k} / \omega_{t e}$.

A second finding of our work is that the mean field Ohm's law contains off-diagonal. spatial parity-breaking contributions associated with test wave density and temperature gradients [last set of terms in Eq. (9)] in addition to the diagonal current diffusion. These contributions arise from test wave-induced modulations of the off-diagonal pieces of the radial flux of parallel electron momentum driven by density and temperature gradients. respectively. Such contributions may be physically thought of as an effective rms diamagnetic velocity, as they induce nonlinear frequency shifts determined by the background turbulence. Although all gradients (i.e., available free energy sources) couple through stresses to drive the large-scale current, they each have different parities. Thus, the conventional wisdom of tearing and twisting parity solutions of the MHD Ohm's law appears to be vitiated in the turbulent, collisionless regime. Significantly, the hyper-resistivity is subdominant compared to both the particle and thermally-driven "current pinches" by a factor $\omega_{k} / \omega_{t e} \ll 1$. Finally, we note that the spectral diffusivity, $D_{W}$, is primarily reactive rather than dissipative and, in this sense, is fundamentally different from the other two coefficients. Taken together, it can be seen that all these results significantly complicate expectations based on naive fluid models. ${ }^{10}$

A few other poinis bear mention. First, since ballistic electron motion does not affect the radial transport of perpendicular heat, radial transport of parallel electron heat and momentum is a factor $\left(\omega_{k} / \omega_{t e}\right)^{2} \ll 1$ smaller than the radial transport of perpendicular 
heat. Second, as mentioned earlier, magnetic fluctuations will alter these results only by taking $\hat{\phi} \rightarrow \hat{\phi}-\left(v_{\|} / c\right) \hat{A}_{\|}$, and consequently introducing a contribution proportional to $\left\langle\hat{b}_{r} \hat{p}_{\|}\right\rangle$in $\Gamma_{e}$. It can readily be seen then that the magnetic contributions are reduced by a factor $\omega_{k} / \omega_{t e} \ll 1$ relative to the electrostatic contributions. Also, while this calculation has been quasilinear in its methodology, it should be noted that considerations of more elaborate self-consistency constraints ${ }^{15}$ will act to couple radial transport to ion dissipation, thereby reducing it even further. Third, the present calculation has focused exclusively on circulating electrons, since it is this class of particles which supports the parallel current. However, the effect of turbulence on bootstrap processes, which requires consideration of trapped electrons, is beyond the scope of the present calculation. Fourth, the effects discussed here are related to the spatial transport of current and hence. should not be confused as being in conflict with experimental observations of neoclassical resistivity. In other words, although total helicity is conserved, it nontheless can get redistributed. ${ }^{16}$ By the same token, our analysis pertains only to the manner in which the plasma current density gets locally redistributed; the total plasma current remains unchanged. Finally, it should be reemphasized that the calculation here refers to the self-consistent transport of parallel current. The problem of fast electron transport in RFP's $^{17}$ is adequately described by test-particle transport models. ${ }^{3,4}$

We conclude with a brief comment on recent work on hyper-resistive ballooning modes, ${ }^{10}$ which claims to demonstrate the possibility of a self-sustaining state of $D_{J^{-}}$ driven turbulence. Our analysis has revealed that ignoring ballistic electron motion, as done in that work, is valid only when $\tau_{c k} \omega_{t e} \sim \omega_{t c} / \omega_{k}<1$. As pointed out earlier, this is never satisfied for drift-Alfvénic turbulence for experimentally-relevant parameters. For a drift wave-like background, this condition requires that the mode spatial scale satisfy $\Delta x<\left(L_{s} / L_{n}\right) \rho_{e}$. Assuming $T_{e} \sim 10 \mathrm{keV}, B=5 \mathrm{~T}$, and $L_{s} / L_{n} \simeq 10$ (a conservatively large estimate for typical $L$-mode plasmas, the focus of Ref. 10), this amounts to $\Delta x<5 \times 10^{-2} \mathrm{~cm}$. But then, such highly-localized modes do not overlap with each other. and hence cause very feeble transport. Hence, the assumptions made in Ref. 10 appear to be internally inconsistent.

\section{ACKNOWLEDGMENTS}

This work was supported by the U.S. Department of Energy Contract \#DE-AC02-76CHO3073 and \#DE-FG03-85ER53275. One of us (PHD) would like to acknowledge an Alfred Sloan Fellowship and an National Science Foundation Principal Young Investigator award. 


\section{References}

${ }^{1}$ J. Schmidt and S. Yoshikawa, Phys. Rev. Lett. 26, 753 (1971).

${ }^{2}$ P. K. Kaw, E. J. Valeo, and P. H. Rutherford, Phys. Rev. Lett. 43, 1398 (1979).

${ }^{3}$ A. R. Jacobson and R. W. Moses, Phys. Rev. A 29, 3335 (1984).

${ }^{4}$ A. B. Rechester and M. N. Rosenbluth, Phys. Rev. Lett. 40, 38 (1979).

${ }^{5}$ H. R. Strauss, Phys. Fluids 29, 3668 (1986).

${ }^{6}$ P. H. Diamond, R. D. Hazeltine, Z. G. An, B. A. Carreras, and H. R. Hicks, Phys. Fluids 27, 1449 (1984).

${ }^{7}$ A. Bhattacharjee and E. Hameiri, Phys. Rev. Lett. 57, 206 (1986).

${ }^{8}$ A. H. Boozer, J. Plasma Phys. 35, 133 (1986).

${ }^{9}$ G. G. Craddock, Ph. D. dissertation, University of Texas at Austin (1987); Phys. Fluids $B$ 3, 316 (1991).

${ }^{10}$ K. Itoh, S.-I. Itoh, A. Fukuyama, M. Yagi, and M. Azumi, "Model of L-mode Confinement in Tokamaks", in Plasma Physics and Controlled Nuclear Fusion Research. 1992, Proceedings of the 14th International Conference, Würzburg (IAEA, Vienna), in press; cf. also K. Itoh, S.-I. Itoh, and A. Fukuyama, Phys. Rev. Lett. 69, 1050 (1992).

${ }^{11}$ J. W. Connor, "Pressure Gradient Turbulent Transport and Collisionless Reconnection. Plasma Physics and Controlled Fusion (in press).

${ }^{12}$ J. F. Drake and R. G. Kleva, Phys. Rev. Lett. 66, 1458 (1991).

${ }^{13}$ H. K. Moffatt, Magnetic Field Generation in Electrically Conducting Fluids (Cambridge. New York, 1978).

${ }^{14}$ W. Horton, D.-I. Choi, P. Terry, and D. Biskamp, Phys. Fluids 23, 590 (1980).

${ }^{15}$ P. W. Terry and P. H. Diamond, Phys. Fluids B 2, 1128 (1991).

${ }^{16}$ G. G. Craddock and P. H. Diamond, Phys. Fluids B 4, 2560 (1992).

${ }^{17}$ J. C. Ingraham, R. F. Ellis, J. N. Downing, C. P. Munson, P. G. Weber, and G. A. Wurden, Phys. Fluids B 2, 143 (1990); K. Hattori, Y. Hirano, T. Shimada, Y. Yagi. Y. Maejima, I. Hirota, and K. Ogawa, Phys. Fluids B 3, 3111 (1991). 
Dr. F. Paoloni, Univ. of Wottongong. AUSTRALIA

Prof. M.H. Brennan, Univ. of Sydney, AUSTRALIA

Plasma Research Lab., Australian Nat. Univ., AUSTRALIA

Prof. I.R. Jones, Flinders Univ, AUSTRALIA

Prot. F. Cap, Inst for Theoretical Physics, AUSTRIA

Prol. M. Heinotor, Instiut for Theoretisctio Physik, AUSTRIA

Prof. M. Goossens, Astronomisch Institurt, BELGIUM

Ecolo Royale Militure, Lab. do Phy. Plasmas, EELGIUM

Commission-Europen, DG. XII-Fusion Prog., BELGIUM

Prot. R. Bouciqud, Rijksuniversibit Gont, BELGIUM

Dr. P.H. Sakanaka, Instituto Fivica, BRAZIL

Institu Necione Do Posquises Especieje-INPE, BRUZIL

Documents Ofico, Abmic Enorgy of Cenada Ld., CANADA

Dr. M.P. Bectynakx, MPB Technotogies, inc., CANADA

Dr. H.M. Skaregard, Univ. of Sackatchowan, CANADA

Prof. J. Toictmann, Univ. of Montreal, CANADA

Prol. S.R. Sreenivasen, Univ. of Calgary, CANADA

Prof. T.W. Johnston, INRS-Energie, CANADA

Dr. R. Bohon, Contro canadion de husion magnétique, CANADA

Dr. C.R. James., Univ. of Aberta, CANADA

Dr. P. Lukde, Komensk tho Univorszita, CZECHOSLOVAKIA

The Librarian, Cutham Laboratory, ENGLAND

Library, R61, Ruthortord Appleton Laboratory. ENGLAND

Mrs. S.A. Hutchineon, JET Librery. ENGLAND

Dr. S.C. Sheme, Univ. of South Pacific, FIJIISLANDS

P. Mehonen, Univ. of Helsinivi, FINLAND

Prol. M.N. Buseac, Ecoto Polytachnique,. FRANCE

C. Nouther, Leb, de Physique des Milioux lonisos, FRANCE

J. Radet, CENCADARACHE - Bat 506, FRANCE

Prot. E. Economou, Univ. of Crote, GREECE

Ms. C. Rinni, Univ. of loamina, GREECE

Dr. T. Mud, Academy Bibliographic Sor., HONG KONG

Preprint Library, Hungarian Acadomy of Sci., HUNGARY

Dr. 8. DasGupta, Saha Inst of Nuclear Ptysics, INDIA

Dr. P. Kaw, Inst. for Plasma Rosearch, INDIA

Dr. P. Rosenaw, Israet Inst of Tectinotogy, ISPAEL

Litrarian, International Conter for Theo Physics, ITALY

Miss C. Do Palo, Associazione EURATOMHENEA, ITALY

Dr. G. Grosso, Istiuto di Fisica del Plasma, ITALY

Prof. G. Rostangni, Istituto Gas lonizzati Del Cnr, ITALY

Dr. H. Yamato, Toshiba Ros Dovol Contor, JAPAN
Prof. I. Kawakami, Hiroshima Univ., JAPAN

Prof. K. Nisnikawa, Hiroshima Univ., JAPAN

Oirector, Jupen Alomic Energy Research Inst. JAPAN

Prof. S. Itoh, Kyushu Univ., JAPAN

Fesearch Into. Cr., National Instit. for Fusion Science, JAPAN

Prot. S. Tanaka, Kyoto Univ., JAPAN

Libray, Kyoto Univ., JAPAN

Prol. N. Inow, Univ. of Tokyo, JAPAN

Secrotary, Plasma Section, Electrobchnical Lab., JAPAN

S. Mori, Tectinical Advieor, MAERI, JAPAN

D. O. Miterai, Kumamoto Inst of Technotogy, JAPAN

J. Hyeon-Sook, Korod Abomic Energy Research Inst, KOREA

D.I. Chad, The Korea Adv. Inst of Sa. \& Tech., KOREA

Prof. B.S. Liby, Univ. of Waikab. NEW ZEALAND

inst of Physica, Chinese Acad Sa PEOPLE'S REP. OF CHINA

Lorey, Inst of Plasma Physios, PEOPLE'S REP. OF CHINA

Tsinghua Univ. Library, PEOPLE'S REPUBLIC OF CHINA

$Z$ L. S.W. Inst Physic, PEOPLE'S REPUBUC OF CHINA

Prof. J.A.C. Cabra, Insturto Superior Tecnico, PORTUGAL

Dr. O. Potrus, Al I CUZA Univ., Romania

Dr. J. de Villiors, Fusion Studies, AEC, S. AFRICA

Prof. M.A. Helberg, Univ. of Natal, S. AFRICA

Prof. D.E. Kim, Pohang Inst. of SCi. \& Tech., SO. KOREA

Prot. C.I.E.M.A.T, Fusion Division Library, SPAIN

Dr. L Sonfto, Univ. of UMEA, SWEDEN

Litray, Royal inst of Tectnology. SWEDEN

Prof. H. Withomson, Chalmors Univ. of Tech., SWEDEN

Centro Phys. Des Plaemas, Ecole Polytoch, SWITZERLAND

Bibliotheix, Inst. Voor Plasma-Fysica, THE NETHERLANDS

Asst. Prot. Dr. S. Cakir, Midde East Tech. Univ., TURKEY

Dr. VA. Gubtiuh, Sci. Res. Inst. Electrophys.I Apparatus, USSR

D. D.D. Ayubv, Siberian Branch of Academy of Sai., USSR

D. GA. Eliseov, I.V. Kurchator Inst, USSA

Lorarian, The Ukr.SSR Academy of Scioncos, USSR

Dr. LM. Kovizinmykh, Inst. of General Physics, USSR

Kemtorsctungsanlage GmbH, Zentrabibtiothek, W. GERMANY

Bibliothok, Inst. For Ptasmaforecting. W. GERMANY

Prof. K. Sctinder, Rutr-Universitat Bochum, W. GERMANY

Dr. F. Wagner, (ASDEX), Max-Planck-Institul, W. GERMANY

Librarian, Max-Plenck-institur, W. GERMANY

Prol. R.K. Janer, Inst of Ptyysics, YUGOSLAVIA 


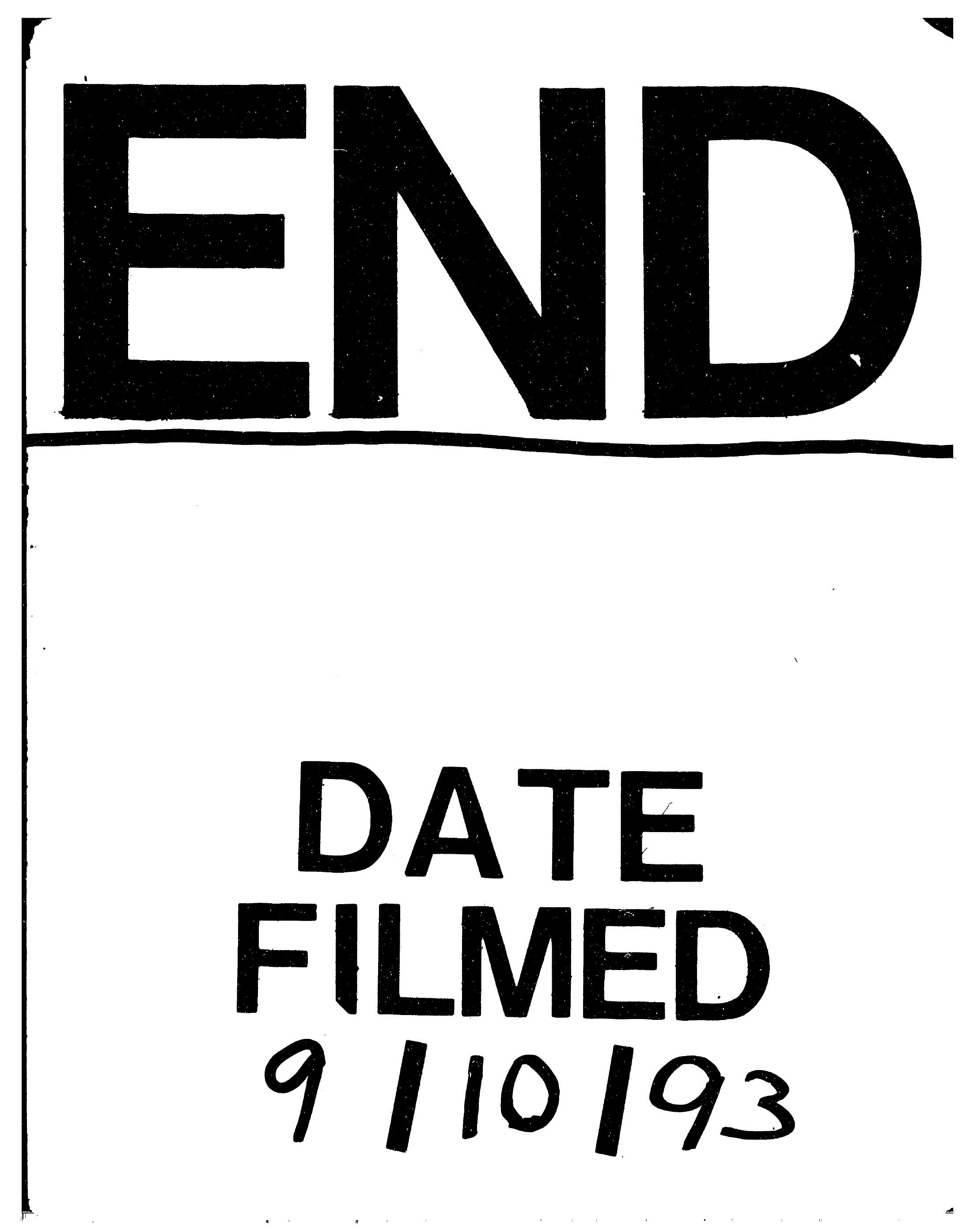

